\title{
METODE PENCEGAHAN PLAGIARISME PADA KELAS TUTORIAL
}

\author{
Fitri Amilia \\ Universitas Muhammadiyah Jember \\ e-mail: fitriamilia@unmuhjember.ac.id
}

\begin{abstract}
Plagiarism is an act of taking or stealing ideas of others, whether intentionally or not. This plagiarism can happen anywhere, by anyone, and in various forms of writing. This plagiarism is referred to as academic crime, so it must be avoided by all parties. This article will examine ways to prevent plagiarism. The scope of this study is in the Indonesian online tutorial at Universitas Terbuka. This article is written based on observations and practices in tutorial activities. In the context of this discussion, plagiarism means writing the same answers from several students during the learning activities. The similarity of answers may be obtained from similar sources. The similariries occur because there is no attempt to write with the correct citation, or paraphrase it. Therefore, it demands creativity and innovation from the tutor in conducting the learning or tutorial, both during discussion time and tutorial task. Creativity is applied in selecting and designing the problem form in discussion activities. This creativity is also related to the skills of the tutor in higher order thinking skills to the students. The concept of innovation is applied in the dynamics of the problem in the tutorial task. Dynamic tutorial will be an indicator of professional educator in performing his duties as tutor. Through the creativity and innovation of tutors, students are indirectly required to answer honestly, thoroughly, and comprehensively. Besides, students are also required to always open the material and questions, because the tutor creates the tutorial class to be dynamic, not static. In this way, the tutorial activities will be a medium and place oflearning for students and tutors.
\end{abstract}

Keywords: creative, discussions, innovative, questions, tutorials, tutorial tasks.

\section{PENDAHULUAN}

Dalam beberapa tahun terakhir, civitas akademika dikejutkan dengan berita tentang plagiarisme. Ada banyak tafsiran atas berita tersebut. Pertama, ada kealpaan dalam menulis. Penulis alpa menggunakan cara sitasi yang tepat. Penulis alpa mencantumkan dalam daftar rujukan, dan masih banyak bentuk lain sebagai bentuk kealpaan penulis. Kedua, menduplikasi karya sendiri pada tulisan yang berbeda. Penulis sudah pernah menulis pada karya sebelumnya. la tidak mencantumkan sitasi yang benar, hingga masuk dalam kategori plagiarisme. Masih banyak tafsiran atas isu plagiarisme tersebut.

Secara definitif, Lako (2012) menyatakan bahwa plagiarisme merupakan tindakan menjiplak, mencuri atau mengambil ide, hasil karya atau tulisan orang lain, baik seluruh, sebagian besar maupun sebagian kecil, untuk jadi ide atau karya tulisan sendiri tanpa menyebutkan nama penulis dan sumber aslinya. Berdasarkan pendapat tersebut, ada beberapa bentuk plagiarisme, yaitu mencuri ide dan menjiplak ide tanpa sitasi. Perbuatan mencuri ide dapat dipastikan tidak akan menulis referensinya, karena ada unsur kesengajaan dalam tindakan plagiarisme. Perbuatan 
menjiplak memiliki dua kemungkinan, jika dilakukan secara sengaja, maka menyerupai tindakan mencuri ide; jika dilakukan tidak sengaja, maka ia alpa dalam menulis sitasi.

Untuk mencegah plagiarisme, banyak yang sudah dilakukan oleh instansi agar dosen dan mahasiswa tidak jatuh dalam lingkaran plagiasrisme. Pertama, memiliki sistem yang mampu mengecek tingkat plagiasi. Kedua, memberlakukan sanksi akademik bagi semua pihak yang terdeteksi melakukan plagiasi. Ketiga, melakukan sosialisasi atas aturan penulisan karya ilmiah. Keempat, membekali dengan teknik penulisan yang benar, terutama materi sitasi.

Karena plagiarisme ini masuk dalam kategori kejahatan intelektual, semua pihak berusaha untuk tidak terjebak dalam bentuk plagiarisme. Artikel ini tidak akan mengkaji usaha untuk mencegah plagiarisme di kalangan dosen, melainkan pada kalangan mahasiswa. Artikel ini akan menyajikan usaha yang bisa dilakukan dosen untuk membiasakan mahasiswa mematuhi aturan dalam menulis sesuai etika akademik, salah satunya antiplagiarisme.

Secara tertulis, pemerintah menegaskan dalam Peraturan Menteri nomor 17 tahun 2010. Dalam peraturan tersebut, mahasiswa yang melakukan tindakan plagiasi dapat mendapatkan sanksi. Dalam pasal 12, mahasiswa yang terbukti melakukan tindakan plagiat akan mendapat sanksi berupa penundaan pemberian hak sebagai mahasiswa, pembatalan nilai, pemberhentian secara tidak hormat, hingga pembatalan ijazah (Peraturan Menteri Pendidikan Nasional Republik Indonesia Nomor 17 Tahun 2010 Tentang Pencegahan dan Penanggulangan Plagiat di Perguruan Tinggi, 2010). Atas dasar inilah, plagiarisme wajib dipahami sebagai tindakan kejahatan intelektual.

Materi tentang plagiarisme ini wajib disampaikan pada mahasiswa. Mereka akan memahami definisi plagiarisme, bentuk plagiarisme, dan akibatnya. Jika perlu, diterapkan perjanjian anti plagiarisme saat diterima menjadi mahasiswa. Perjanjian anti plagiarisme saat menjadi mahasiswa akan menuntut mahasiswa menulis dengan benar dan jujur. Kenyataannya, peraturan anti plagiasi hanya diberlakukan pada saat menulis karya ilmiah sebagai tugas akhir. Jika hal tersebut belum bisa diterapkan, maka dalam setiap kegiatan pembelajaran, dosen, tuton, tutor wajib mempraktikkan anti plagiarisme pada mahasiswa.

Dalam kegiatan pembelajaran secara online, tutor memiliki peranan penting dalam menjaga nilai-nilai akademis pada setiap tulisan mahasiswa. Tutor telah menyampaikan pada mahasiswa bahwa kegiatan diskusi dan juga tagihan tugas harus bebas dari plagiarisme. Tutor tidak menoleransi plagiarisme yang dilakukan mahasiswa dalam bentuk apa pun. Dengan demikian, mahasiswa diharapkan mampu menjaga setiap tulisan dari berbagai bentuk plagiarisme.

Untuk mencapai hal itu, tutor harus kreatif dan inovatif dalam mengelola kelas tutorial. Makna kreatif mengacu pada pemilihan bentuk soal yang digunakan pada diskusi dan juga tugas tutorial. Makna inovatif merujuk pada kedinamisan soal pada setiap diskusi dan tugas tutorial.

Bentuk soal dalam diskusi dan tugas tutorial tidak selalu untuk mengukur pengetahuan mahasiswa sesuai dengan informasi yang tertulis dalam modul. Soal tersebut berfungsi untuk mengukur pemahaman, penerapan, analisis, sintesis, dan evaluasi. Keenam fungsi tersebut dikenal dengan nama taksonomi Bloom (1956). Keenam hal tersebut merupakan enam level ranah kognitif (Krathwohl, et al., 2001). Keenam tersebut bisa diaplikasikan dalam soal diskusi dan juga tutorial.

Ditinjau dari tingkat berpikir dalam pembelajaran, level pengetahuan, pemahaman, dan penerapan merupakan level rendah, sedangkan analisis, sintesis, dan evaluasi merupakan level tinggi (Utari, 2011). Disebut level rendah karena pebelajar masih memahami sesuai dengan teks buku. Disebut level tinggi karena pebelajar sudah memahami teks secara komprehensif, hingga mampu menemukan pola atau desain atas materi yang dipelajari. Tujuan akhir dari berpikir level 
tinggi adalah mampu berpikir kritis, tidak selalu menerima informasi secara pasif, tetapi mampu menelaah secara utuh. Berpikir kritis juga akan diimbangi oleh berpikir evaluatif (Adams, 2015).

Keenam level taksonomi Bloom telah direvisi (Krathwohl, 2002). Tingkatan tersebut adalah mengingat, memahami, mengaplikasikan, menganalisis, mengevaluasi, dan mencipta. Perubahan taksonomi Bloom tersebut terletak pada perubahan istilah pada level pertama dan perubahan urutan level 5 pada taksonomi lama menjadi level 6 pada taksonomi yang baru (Krathwohl, 2002).

Indikator yang bisa dipakai untuk mengukur level tersebut adalah dengan menggunakan kata kerja operasional atau kata kunci. Tabel 1 contoh kata kunci pada tiap level.

Tabel 1. Level Berpikir pada Ranah Kognitif Bloom.

\begin{tabular}{cll}
\hline Level & \multicolumn{1}{c}{ Kategori } & \multicolumn{1}{c}{ Kata Kerja } \\
\hline 1 & Remember & Mendefinisikan, mengidentifikasi, menyebutkan, dst \\
2 & Understanding & Menguraikan, membedakan, merangkum, dst \\
3 & Apply & Melengkapi, menemukan, membuktikan, dst \\
4 & Analyze & Menganalisis, membuat skema/diagram, menunjukkan \\
& & hubungan beberapa variabel, dst \\
5 & Evaluate & Mendesain, mengarang, menyimpulkan, dst \\
6 & Create & Mengaji ulang, mengoreksi, mengkritik, dst \\
\hline
\end{tabular}

Berdasarkan tingkatan tersebut, soal-soal dalam diskusi dan tutorial seharusnya bisa mengajar mahasiswa pada tingkatan berpikir tingkat tinggi (higher order thingking skill), pada level 4 sampai 6.

Kreativitas dalam menyusun soal sesuai dengan level berpikir tingkat tinggi akan membuat mahasiswa lebih mampu memahami modul secara komprehensif. Mahasiswa juga tidak akan belajar dari satu sumber, sehingga tujuan menepis plagiarisme bisa dicapai.

Selain kreativitas, dibutuhkan usaha untuk menyusun soal secara dinamis. Ada perubahan soal dari semester ke semester. Dengan demikian, pembelajar bukan orang yang menghafal soal dan jawaban, tetapi juga belajar bersama mahasiswa dalam kegiatan diskusi dan tutorial.

\section{METODE}

Artikel ini disusun berdasarkan pengalaman dan observasi di kelas tutorial. Kelas tutorial yang menjadi sumber data adalah kelas tutorial 67 dan 68 pada semester 2017.1 dan kelas tutorial 37 ddan 38 pada 2017.2. Metode pengumpulan data dengan dokumentasi yaitu menemukan keterampilan berpikir rendah dan tingkat tinggi pada mahasiswa di kegiatan diskusi dan tutorial. Pengumpulan data juga diambil dari kajian teoretis sebagai upaya untuk mengurasi plagiasi di kelas tutorial. Metode analisis yang digunakan adalah deskriptif, yaitu menyajian upaya untuk menghindari plagiasi di kelas tutorial.

\section{HASIL DAN PEMBAHASAN}

\section{Kreativitas Tutor Dalam Mendesain Soal sesuai Level Berpikir}

Dalam taksonomi Bloom, keterampilan berpikir level rendah berada pada kategori mengingat, memahami, dan menerapkan. Keterampilan berpikir tingkat tinggi berada pada kategori menganalisis, mengevaluasi, dan mencipta. Ada banyak kata kerja operasional pada keenam level tersebut. Berikut penjelasan tiap-tiap level. 
Level pertama, mengingat atau remember. Kata kerja operasional yang digunakan adalah mendefinisikan, menyusun daftar, menjelaskan, mengingat, mengenali, menemukan kembali, menyatakan, mengulang, mengurutkan, menamai, menempatkan, menyebutkan (Utari, 2011). Contoh soal pada level ini adalah menanyakan definisi, misalnya pada soal "apa yang disebut kalimat efektif? atau apa pengertian kalimat efektif?" Pertanyaan tersebut merupakan pertanyaan pada level mengingat. Disebut soal mengingat, karena mahasiswa akan kembali pada bentuk definisi yang pernah dibaca.

Pola pertanyaan seperti ini biasanya akan mendekatkan mahasiswa dengan plagiasi. Mahasiswa akan mencari pengertian, dan menjadikannya jawaban pada diskusi atau tutorial. Bentuk soal pada level ini terbukti mendekatkan mahasiswa dengan plagiasi. Ada banyak jawaban yang secara definitif sama. Persamaan tampak pada diksi, susunan kalimat, bahkan contoh yang ditulis pada jawaban. Berdasarkan temuan ini, hendaknya tutor menghindari pertanyaan definisi atas suatu konsep atau teori.

Level kedua, memahami atau understanding. Kata kerja operasional meliputi menerangkan, menjelaskan, menerjemahkan, menguraikan, mengartikan, menyatakan kembali, menafsirkan, menginterpretasikan, mendiskusikan, menyeleksi, mendeteksi, melaporkan, menduga, mengelompokkan, memberi contoh, merangkum menganalogikan, mengubah, memperkirakan (Utari, 2011). Contoh soal pada level ini adalah "Mengapa mendengarkan radio termasuk menyimak ekstensif? atau memperbaiki kalimat sesuai dengan ejaan bahasa Indonesia" Pada soal ini, mahasiswa akan menjelaskan sesuai dengan pemahaman mereka.

Bentuk soal pada level memahami ini menuntut mahasiswa menjelaskan suatu hal atau fenomena. Pada level ini, plagiasi lebih bisa dihindari dibandingkan soal pada level 1. Ditemukan jawaban mahasiswa yang menjelaskan secara logis, disertasi alasannya. Namun, lebih banyak mahasiswa yang menjawab dengan remeh. Hal ini tampak pada jawaban yang tekstual sesuai dengan penjelasan dalam buku referensi.

Level ketiga, menerapkan atau apply. Kata kerja operasional meliputi memilih, menerapkan, melaksanakan, mengubah, menggunakan, mendemonstrasikan, memodifikasi, menginterpretasikan, menunjukkan, membuktikan, menggambarkan, mengoperasikan, menjalankan memprogramkan, mempraktekkan, memulai (Utari, 2011). Contoh soal pada level ini adalah "Ringkaslah teks berikut ini...."

Pada soal tersebut, plagiasi lebih bisa dihindari dibandingkan dua level sebelumnya. Dalam usaha meringkas, setiap mahasiswa memiliki cara sesuai dengan pemahaman yang mereka baca dalam buku referensi. Namun, karena teks yang disajikan tidak sama, mahasiswa dituntut untuk menerapkan teori dalam praktik merangkum. Namun, pada tahapan ini, masih memungkinkan ditemukan plagiasi, bila teks yang dipilih disajikan dalam buku referensi. Dengan demikian, dibutuhkan kreativitas tutor untuk memilih teks untuk soal merangkum.

Level keempat, menganalisis atau analyze. Kata kerja operasional meliputi mengaji ulang, membedakan, membandingkan, mengkontraskan, memisahkan, menghubungkan, menunjukan hubungan antara variabel, memecah menjadi beberapa bagian, menyisihkan, menduga, mempertimbangkan mempertentangkan, menata ulang, mencirikan, mengubah struktur, melakukan pengetesan, mengintegrasikan, mengorganisir, mengerangkakan (Utari, 2011). Contoh soal pada analisis ini adalah membandingkan dua teks, lalu meminta mahasiswa mencari persamaan dan perbedaan antarteks. Sama dengan level sebelumnya, teks ini menuntut kreativitas tutor. Tutor memiliki kumpulan teks yang tidak disajikan dalam buku referensi, sehingga mahasiswa akan belajar dengan sungguh-sungguh untuk bisa melakukan analisis. 
Pada level ini, plagiasi lebih bisa ditekan. Pada level ini, temuan plagiasi akan sangat minim. hal ini disebabkan oleh ada dorongan untuk melakukan analisis yang tidak dijumpai di buku, sehingga mahasiswa tidak mudah memindah teks dari buku dalam kelas tutorial.

Level kelima, mengevaluasi atau evaluate. Kata kerja operasional meliputi mengkaji ulang, mempertahankan, menyeleksi, mempertahankan, mengevaluasi, mendukung, menilai, menjustifikasi, mengecek, mengkritik, memprediksi, membenarkan, menyalahkan (Utari, 2011). Contoh soal yang bisa dipakai dalam kegiatan tutorial adalah menilai keutuhan sebuah teks baik menemukan kesalahan atau kebenaran di dalamnya. Misalnya, dihadirkan sebuah teks eksposisi tentang fungsi Bahasa Indonesia dalam kegiatan pembelajaran, mahasiswa diminta mengevaluasi paragraf, ejaan, dan kata baku di dalamnya.

Pada level ini, plagiasi akan lebih sulit ditemukan dibandingkan level sebelumnya. Soal seperti cocok untuk disajikan di tugas tutorial. Dalam tugas tutorial, antarmahasiswa tidak bisa saling melihat jawaban, sehingga bisa dipastikan, plagiasi sulit atau bahkan tidak ditemukan.

Level keenam, mencipta atau create. Kata kerja operasional meliputi merakit, merancang, menemukan, menciptakan, memperoleh, mengembangkan, memformulasikan, membangun, membentuk, melengkapi, membuat, menyempurnakan, melakukan inovasi, mendisain, menghasilkan karya (Utari, 2011). Contoh soal pada level ini melanjutkan tugas evaluasi, yaitu menyusun teks secara mandiri dengan ketentuan dan kriteria tertentu.

Menyusun teks secara mandiri akan memaksa mahasiswa untuk berpikir lebih kritis agar menghasilkan teks yang mencerminkan diri mereka sendiri. Oleh sebab itu, tutor harus memberikan rambu-rambu dalam menyusun teks. Tutor menentukan tema sesuai dengan jurusan mahasiswa. Tutor meminta mahasiswa memberikan contoh kasus terbaru yang sedang terjadi di Indonesia, dan seterusnya. Melalui rambu-rambu tersebut, pada level ini, plagiasi mutlak tidak akan ditemukan.

Berdasarkan uraian tersebut, semakin tinggi level soal, maka semakin menepis plagiasi dari kelas tutorial. Untuk itu, dibutuhkan kreativitas tutor dalam mendesain, mengolah, mengoleksi soal. Dengan demikian, setiap tutor memiliki bank soal yang dapat menjadi media dan sumber belajar pada kelas tutorial. Melalui bank soal tersebut, tutor dapat mengganti soal dalam diskusi dan tugas tutorial dalam setiap semester.

\section{Inovasi Tutor Dalam Kegiatan Tutorial}

Selama beberapa semester, di kelas peneliti, soal pada diskusi pada tugas tutorial tidak mengalami perubahan. Di kelas tutorial, peneliti hanya mengubah setting yang berhubungan dengan waktu tutorial, dan beberapa setting lainnya. Peneliti berasumsi, setiap semester selalu ada perubahan mahasiswa di kelas tutorial, sehingga soal yang sama bisa saja dipakai untuk kegiatan tutorial.

Selama itu pula, sering dijumpai beberapa jawaban yang sama dan atau mirip. Jawaban sama merujuk pada tingkat kemiripan seratus persen. Bisa dipastikan jawaban sama ini merupakan mengandung plagiasi. Jawaban sama ini terjadi antarmahasiswa pada semester yang sama, dan antarmahasiswa pada semester yang berbeda. Adapun jawaban mirip masih ditemukan sedikit perbedaan pada jawaban mahasiswa. Bila menggunakan ilustrasi, presentasi jawaban sama adalah 100\%, jawaban mirip dimulai dari 50-90\%.

Fenomena ini sempat didiskusikan teman tutor di kelas lain. Jawaban mereka sama, fenomena jawaban sama juga terjadi dalam kelas yang pada semester yang sama, juga pada semester yang berbeda. Namun, hasil diskusi pada saat itu, mungkin jawaban sama dan mirip karena membaca referensi yang sama. Belum ada jawaban yang memuaskan saat diskusi itu. 
Sempat terpikir untuk mengubah soal. Namun, mahasiswa yang berbeda pada setiap semester tentu tidak berdampak secara signifikan.

Semester ini, peneliti mengalami perpindahan kelas tutorial. Soal yang dibuat oleh tutor sebelumnya berbeda dengan soal di kelas peneliti. Ini sangat menarik. Peneliti memiliki asumsi, tutor boleh saja memiliki soal yang berbeda untuk mengukur dan menghidupkan suasana akademik pada tutorial. Berdasarkan pengalaman ini, peneliti mengganti semua soal tutorial untuk bisa mengajak mahasiswa pada level yang lebih tinggi, yaitu memiliki keterampilan berpikir level tinggi.

Dalam beberapa kegiatan diskusi, perubahan soal pada diskusi dan tugas tutorial menunjukkan perubahan pola jawaban mahasiswa. Pada kegiatan diskusi, peneliti hampir tidak menjumpai jawaban yang sama atau mirip. Mereka mampu menjelaskan sesuai dengan pemahaman mereka, dan mampu mencontohkan dari kehidupan nyata yang dirasakannya.

Ada hal yang menarik, pada tugas tutorial ke-2, ada jawaban mahasiswa untuk soal yang ada pada kelas tutorial semester lalu. Semester ini peneliti sudah mengganti pola soal. Soal yang disajikan berjumlah empat, sedangkan soal di semester lalu berjumlah enam. Bentuk soal juga sudah berubah, sehingga meminta jawaban yang berbeda. Temuan pengiriman jawaban untuk tugas tutorial yang sama dengan soal di semester lalu menunjukkan prediksi mahasiswa bahwa soal tutorial tidak pernah berubah. Ini tidak hanya terjadi pada seorang mahasiswa saja, sehingga peneliti menyatakan ini sebagai fenomena tutorial. Atas dasar ini, tutor wajib mengganti soal-soal pada kegiatan diskusi dan tugas tutorial.

Penggantian ini disebut kedinamisan tutorial. Tutorial memang dilaksanakan delapan kali dengan distribusi yang telah ditentukan. Namun, isi dari kegiatan tutorial harus dinamis, berubah dari semester ke semester, sehingga plagiasi jawaban dari semester sebelumnya tidak ditemukan lagi.

Hal ini sesuai dengan kompetensi profesional guru. Dalam konteks ini, tutor juga bisa disebut dengan guru dalam pembelajaran online. Dalam penilaian kinerja guru disebutkan empat kompetensi profesional meliputi persiapan, penyampaian, dan evaluasi materi pembelajaran (2008). Pada tahap persiapan, pendidik wajib menyiapkan materi yang update, artinya materi tidak boleh kering dan statis. Pendidik yang profesional selalu menggunakan materi dinamis, contoh yang berubah, penjelasan yang bertambah, dan lain sebagainya. Sebaliknya, pendidik yang tidak profesional dalam persiapan ini, tidak pernah mengembangkan materi dari semester ke semester. Dalam konteks tutorial, tutor yang tidak pernah memodifikasi soal juga masuk dalam kategori tutor yang kurang profesional. Akibat dari kestatisan ini, fenomena plagiasi akan selalu hadir dalam kelas tutorial.

Pada tahap penyampaian, pendidik harus bisa menciptakan suasana yang kondusif dan hidup. Dalam konteks tutorial, tutor tidak hanya menilai diskusi siswa, tetapi memberikan umpan balik, bisa berupa pujian, saran, kritik, dan bentuk umpan balik yang lain. Umpan balik tidak hanya diakhir tugas, saat diskusi, tutor bisa memberikan umpan balik. Melalui umpan balik ini, mahasiswa bisa kembali belajar beradasarkan umpan balik yang diberikan.

Pada tahap evaluasi, pendidik bisa memilih tes yang tepat sesuai dengan kompetensi yang akan diukur. Tutor bisa memilih bentuk tes yang tepat. Pada bagian ini, telah dibahas pada subbab kreativitas tutor dalam memilih soal. Dalam konteks ini, pembelajharan tutorial disajikan secara online, aplikasi dari ini semua adalah kedinamisan kegiatan tutorial.

\section{SIMPULAN}

Plagiarisme merupakan tindak kejahatan intelektual yang harus dihindari atau bahkan dihilangkan dari semua kegiatan akademik, begitu pula dalam kegiatan tutorial. Untuk itu, dibutuhkan kreativitas dan inovasi tutor dalam mendesain soal pada kegiatan diskusi dan tugas tutorial. Melalui 
kreativitas mendesain soal pada keterampilan berpikir level tinggi, plagiasi ini bisa dihindari atau bahkan tidak ditemukan dalam kelas tutorial. Melalui kedinamisan soal tiap semester, mahasiswa mau belajar kembali dan tetap bisa mempraktikkan berpikir level tinggi.

\section{REFERENSI}

Adams, N. E. (2015). Bloom's Taxonomy of Cognitive Learning Objectives. Journal of the Medical Library Association , 152-153.

Bloom, B. S., Engelhart, M. D., Furst, E. J., Hill, W. H., \& Krathwohl, D. R. (1956). Taxonomy of Educational Objectives: The Classification of Educational Goals. Handbook 1 Cognitive Domain. New York: David McKay.

Direktorat Tenaga Pendidikan. (2008). Penilaian Kinerja Guru. Jakarta: Departemen Pendidikan Nasional.

Kementerian Pendidikan dan Kebudayaan. (2010, Agustus 16). Peraturan Menteri Pendidikan Nasional Republik Indonesia Nomor 17 Tahun 2010 Tentang Pencegahan dan Penanggulangan Plagiat di Perguruan Tinggi. Peraturan Menteri Pendidikan Nasional Republik Indonesia Nomor 17 Tahun 2010 Tentang Pencegahan dan Penanggulangan Plagiat di Perguruan Tinggi . Jakarta, Indonesia, Indonesia: Kementerian Pendidikan dan Kebudayaan.

Krathwohl, D. R. (2002). A Revision of Bloom's Taxonomy: An Overview. Theori Into Practice , 212218.

Krathwohl, D. R., Airasian, P. W., Cruikshank, K. A., Mayer, R. E., Pintrich, P. R., Raths, J., et al. (2001). A Taxonomy for Learning, Teaching, and Assessing: A Revision of Bloom's Taxonomy of Educational Objectives. . New York: Longman.

Lako, A. (2012, Juli 2). https://storage.kopertis6.or.id/. Dipetik Maret 23, 2018, dari https://storage.kopertis6.or.id/kelembagaan/: https://storage.kopertis6.or.id/kelembagaan/ARTIKEL\%20PLAGIARISME\%20AKADEMIK1.p df

Utari, R. (2011). http://www.academia.edu/. Dipetik April 5, 2018, dari http://www.academia.edu/: http://www.academia.edu/download/35904082/1-Taksonomi_Bloom_-_Retno-okmima_abstract.pdf. 